\title{
SPONTANEOUS PNEUMOPERICARDIUM IN A CASE OF CAVITATING PULMONARY METASTASIS WITH PULMONARY-PERICARDIAL FISTULA
}

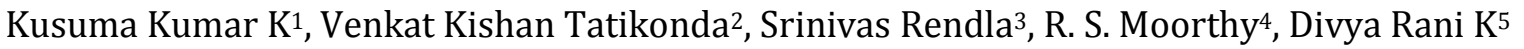

\section{HOW TO CITE THIS ARTICLE:}

Kusuma Kumar K, Venkat Kishan Tatikonda, Srinivas Rendla, R. S. Moorthy, Divya Rani K. "Spontaneous Pneumopericardium in a Case of Cavitating Pulmonary Metastasis with Pulmonary-Pericardial Fistula". Journal of Evolution of Medical and Dental Sciences 2014; Vol. 3, Issue 22, June 02; Page: 6133-6139,

DOI: $10.14260 /$ jemds/2014/2713

ABSTRACT: Pneumopericardium is collection of air in the pericardial cavity. Though this condition is uncommon, there are many causes for pneumopericardium, of which, trauma is the commonest. This case report is a presentation of an uncommon condition of cavitating secondary deposit in the lung from carcinoma tongue, with a fistulous communication with the pericardial cavity causing hydropneumopericardium. Various causes of pneumopericardium, its clinical implications, complications, diagnosis and management are discussed briefly.

KEYWORDS: Pneumopericardium, Pericardium, carcinoma tongue.

CASE REPORT: A 35 year old woman was referred to the department of Radiodiagnosis for CT chest with history of progressing dyspnoea. She was advised a chest CT in December 2013 for dyspnoea which showed a thin walled cavity in the left upper lobe. The women had a history of carcinoma tongue for which she had taken radiotherapy, 6 months prior to the present visit to the hospital.

Chest $X$ ray (Fig. 1) showed thin walled cavity in the left upper zone with wide mediastinal border. Pericardium was elevated with air lucency between the pericardium and cardiac margin (both right and left side). There was an air fluid level in left lower zone, in the confines of the elevated pericardium. CT scan showed a large thin walled cavitory lesion in the left upper lobe with broad base toward the mediastinum. (Fig. 2, 3)

Lung window shows air in the pericardial cavity extending up to the root of ascending aorta. A fistulous connection (Arrow in Fig. 5, Fig. 6 and 7) between the said cavity and the pericardial space was clearly depicted in the lung window (pulmonary pericardial fistula). Mediastinal/soft tissue window (Fig. 8 and 9) showed multiple focal soft tissue density lesions in the chest wall.

There was a lytic lesion in the right iliac bone with some soft tissue component. (Fig. 10)

The patient had a CT chest done in December 2013, (Fig. 4) which showed a cavitory lesion in the left upper lobe, much smaller than that seen in the present scan.

\section{PROVISIONAL DIAGNOSIS: PULMONARY PERICARDIAL FISTULA IN A CASE OF CAVITATING METASTASIS FROM CARCINOMA TONGUE}

FURTHER MANAGEMENT: Patient was referred to cardiothoracic surgeon for further management of the fistula causing dyspnoea.

\section{OTHER DIFFERENTIAL DIAGNOSES:}

1. Tuberculous cavity with fistulous communication with the pericardium.

2. Lung abscess communicating with the pericardium.

3. Primary bronchogenic carcinoma with a lung cavity communicating with pericardium. 
DISCUSSION: Pneumopericardium is defined as the presence of air in the pericardial space.[1]

Pneumopericardium was first described by Bricheteau in 1844 who named bruit de Moulin (water wheel sound) associated with pneumopericardium.[7]

The amount of air required to produce haemodynamic changes depends on the volume and rate of introduction ${ }^{[1]}$ :

- Haemodynamic changes may occur with as little as $60 \mathrm{ml}$ of air if it is introduced rapidly.

- Up to $500 \mathrm{ml}$ may accumulate into the pericardium without marked effect if introduced slowly into the pericardial space.

Since the patient in the present case had no complaints other than dyspnoea, the condition was considered to have been slowly progressing.

\section{ETIOLOGY:}

Causes of Pneumopericardium are broadly classified as:

1. Traumatic: Blunt or penetrating chest injury and barotrauma are included in this category Barotrauma is usually secondary to positive pressure ventilation (both invasive and noninvasive) most commonly occurring in neonatal practice Cases associated with severe asthma, prolonged labour and cocaine inhalation.

2. Fistulation between pericardium and a hollow or air-containing structure e.g. air in the pleural space, pulmonary substance, bronchial tree, gastrointestinal tract Fistulous communication between the malignant lung mass and the pericardial cavity.[1,2] Fistulous communication between cavitory infection of the lung and pericardial space.[4], [5]\&[6] Gastropericardial fistula complicating peptic ulcer disease. [3]

3. Much less common is secondary to gas production de novo by microorganisms invading the pericardial sac e.g. Clostridium perfringens and Klebsiella.

DIAGNOSIS: The patient with a small pneumopericardium may be asymptomatic and the cardiac examination may be normal.

In large pneumopericardium the patient may be symptomatic, the percussion on the chest may be tympanic and heart sounds may be metallic. The commonest symptoms are dyspnea and precordial chest pain. Other symptoms if present are associated with the underlying etiology.

It may only be diagnosed incidentally on a chest radiograph and the gas usually does not rise above the upper limit of the pericardium in the erect position, which differentiates the pneumopericardium from pneumomediastinum.

Computed tomography is the modality of choice in identifying the presence and also determining the cause of pneumopericardium.

MANAGEMENT: Pneumopericardium unlike pneumothorax often does not require any specific treatment and is usually self-limiting. The treatment of small or asymptomatic pneumopericardium is usually directed toward the underlying disease.

Treatment is required in cases of large and symptomatic pneumopericardium or in patients of tension pneumopericardium, which can be a needle aspiration or tube decompression. 
COMPLICATION: Tension pneumopericardium leading to cardiac tamponade occasionally complicates pneumopericardium.

This complication is because of a ball valve mechanism which prevents air from leaving the pericardial space.

CONCLUSIONS: In the present case, the patient had a history of carcinoma of tongue and had undergone radiation therapy 6 months back.

The cavity in the left upper lobe is considered as a secondary deposit as there are multiple chest wall soft tissue secondary deposits, pelvic bone secondaries and the rest of the lung shows no signs of acute or chronic infection or inflammation. This needs to be proved by biopsy, however, rapid growth of the cavity in comparison with pervious CT scan indicates malignancy.

This lesion showed fistulous communication with the pericardium (pulmonary pericardial fistula) causing hydropneumopericardium.

\section{REFERENCES:}

1. Stacey $S$ et al. A case of spontaneous tension pneumopericardium. Br J Cardiol 2004;11:32-14

2. Joon Beom Seo, Jung-Gi Im, Jin Mo Goo, Myung Jin Chung, and Mi-Young Kim. Atypical Pulmonary Metastases: Spectrum of Radiologic Findings. Radio Graphics 2001 21:2, 403-417.

3. A. A. R. Gossage, P. W. Robertson and S.F.Stephenson. Spontaneous pneumopericardium. Thorax (1976), 31, 460.

4. Abeer A. Arab, Maan A. Kattan, Walid A. Alyafi, and Jamal A. Alhashemi. Bronchopleuropericardial fistula complicating staphylococcal sepsis. Saudi J Anaesth. 2011 Oct-Dec; 5(4): 434-437.

5. Owens, C.M., Graham, T.R., Wood, A.J. and Newland, A.C. (1990), Bronchopericardial fistula and pneumopericardium complicating invasive pulmonary aspergillosis. Clinical \& Laboratory Haematology, 12: 351-354.

6. Kulczycki M, Wodala E. Pulmonary-pericardial fistula as a complication of fibro-cavernous chronic tuberculosis. Gruzlica. 1968 Mar; 36 (3):281-2.

7. Arda K, Eldem O, Sigirci A, Ozkan FO. Spontaneous pneumopericardium and pneumomediastinum. Asian Cardiovasc Thorac Ann 2000;8: 59-61. 


\section{CASE REPORT}

Fig. 1: Chest X-ray showing thin walled cavity in left upper zone with broad base towards the mediastinum and air lucency surrounding the heart, elevating the pericardium.

There is a horizontal fluid level in the left lower zone, obliterating the cardiac border s/o hydropneumopericardium

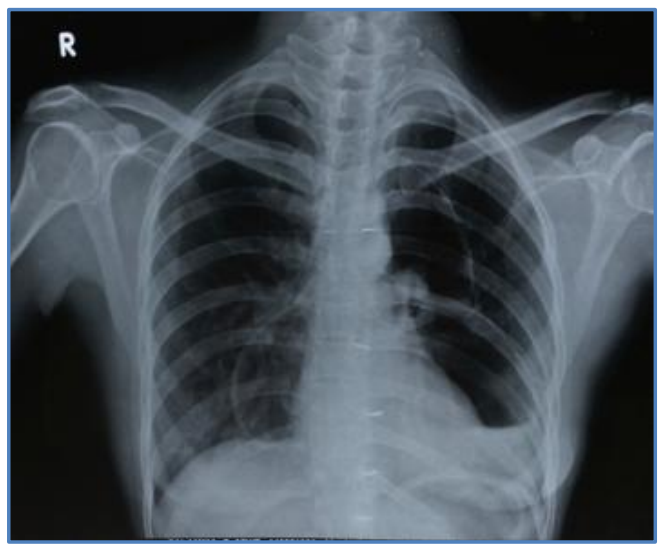

\section{Figure 1}

Fig. 2: CT chest lung window shows a large, thin walled cavity in right upper lobe.

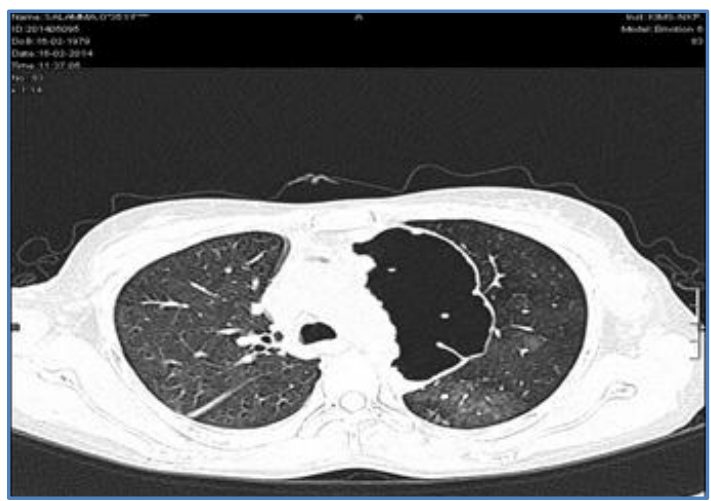

\section{Figure 2}

Fig. 3: Coronal CT image of chest - lung window shows clearly the thin walled cavity.

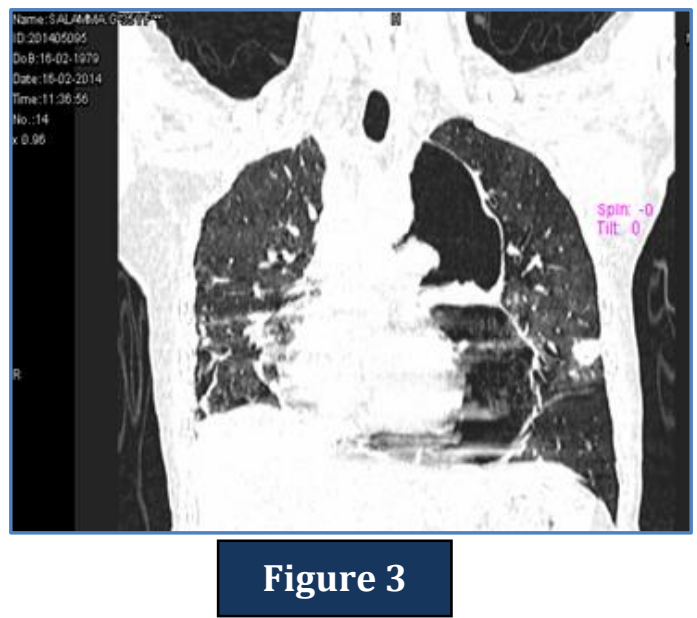




\section{CASE REPORT}

Fig.4: Previous CT scan done in December 2013, at another centre, showing small cavity in the left upper lobe.

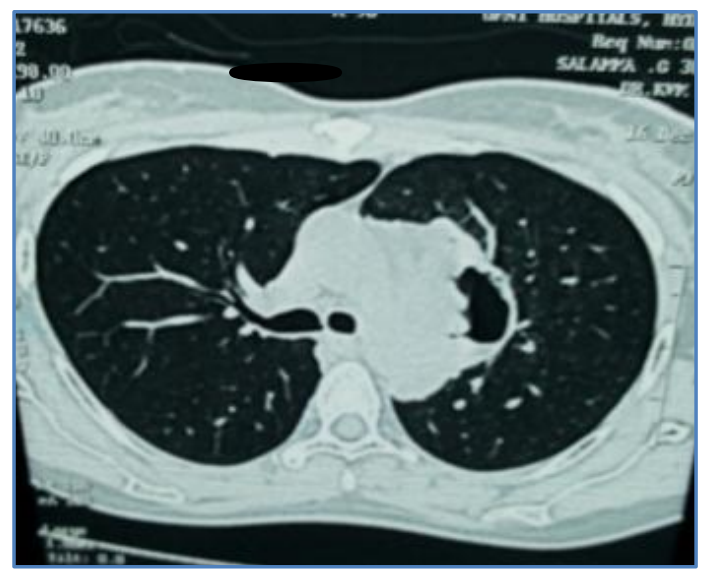

Figure 4

Fig. 5: Lung window showing communication between the cavitory lesion of the lung and pericardium.

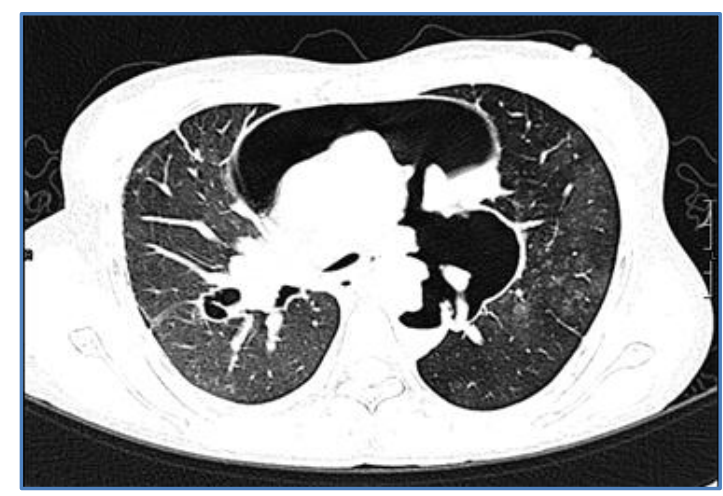

Figure 5

Fig. 6: Coronal image of $\mathrm{CT}$ chest shows clearly the communication of the cavity with pericardial air.

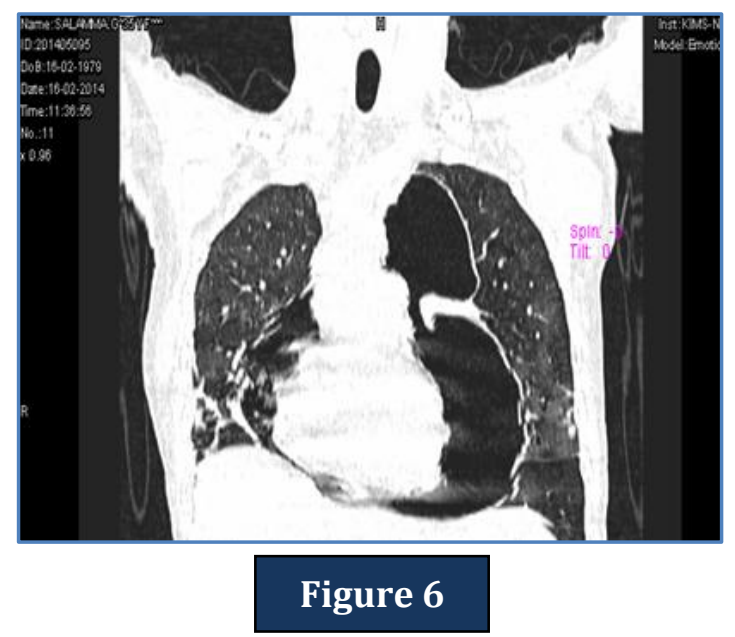




\section{CASE REPORT}

Fig.7: Sagittal image of CT chest shows fistulous communication between the cavity in the lung and the pericardial air.

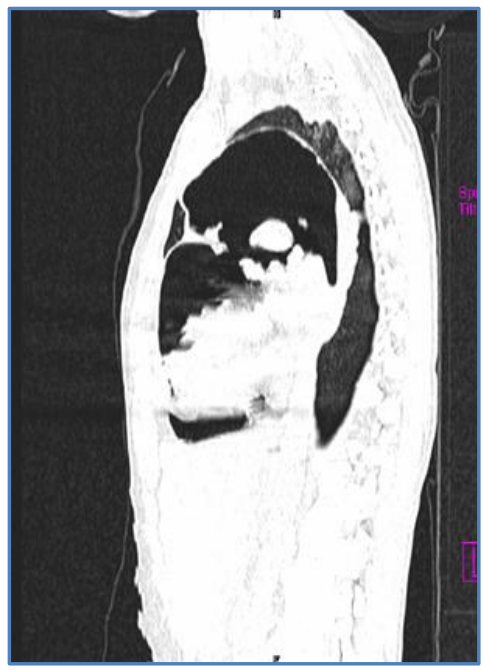

Figure 7

Fig. 8 and 9: Soft tissue window images showing metastatic deposits in the chest wall.

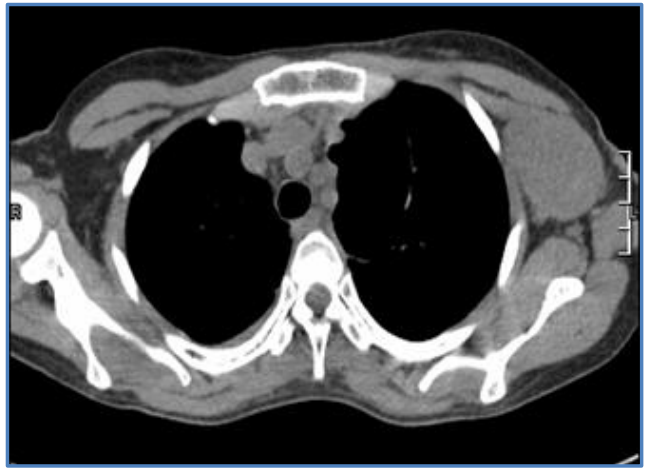

Figure 8

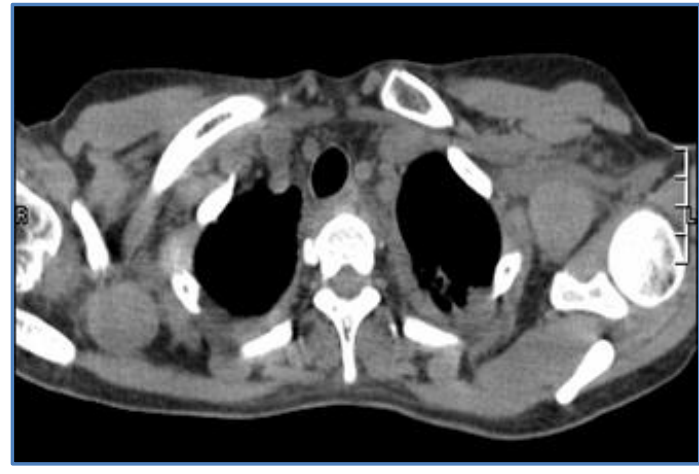

Figure 9

Fig. 10: CT scan of the pelvis, Soft tissue window showing lytic lesion in the right ilium with soft tissue component into the gluteal muscles, displacing the fat planes between them.

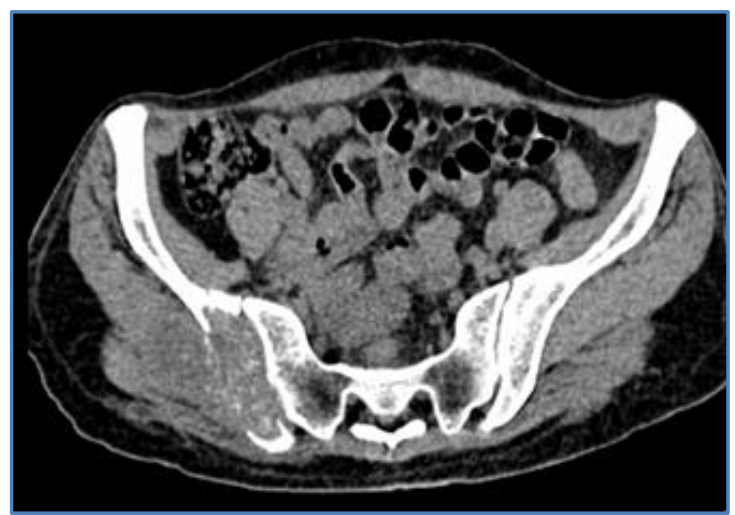

Figure 10 


\section{CASE REPORT}

\section{AUTHORS:}

1. Kusuma Kumar K.

2. Venkat Kishan Tatikonda

3. Srinivas Rendla

4. R. S. Moorthy

5. Divya Rani K.

\section{PARTICULARS OF CONTRIBUTORS:}

1. Assistant Professor, Department of Radiodiagnosis, Kamineni Institute of Medical Sciences, Narketpally.

2. Assistant Professor, Department of Radiodiagnosis, Kamineni Institute of Medical Sciences, Narketpally.

3. Resident, Department of Radiodiagnosis, Kamineni Institute of Medical Sciences, Narketpally.

4. Professor \& HOD, Department of Radiodiagnosis, Kamineni Institute of Medical Sciences, Narketpally.
5. Resident, Department of Radiodiagnosis, Kamineni Institute of Medical Sciences, Narketpally.

\section{NAME ADDRESS EMAIL ID OF THE CORRESPONDING AUTHOR:}

Dr. Kusuma Kumar K, \#103, P \& T Colony,

Trimulgherry,

Secunderabad - 500015.

Email: kota_kusum@yahoo.co.in

Date of Submission: 05/05/2014. Date of Peer Review: 06/05/2014. Date of Acceptance: 23/05/2014. Date of Publishing: 31/05/2014. 